\title{
Standardized Uptake Values Highly Correlate with Tumor Size and Fuhrman Grade in Patients with Clear Cell Renal Cell Carcinoma
}

\author{
Emre Can Polat ${ }^{1 *}$,Alper Otunctemur ${ }^{2}$, Emin Ozbek $^{2}$, Huseyin Besiroglu $^{2}$, Murat \\ Dursun $^{2}$, Kutan Ozer ${ }^{3}$, Mustafa Ozan Horsanali ${ }^{3}$
}

\begin{abstract}
Background: We investigated the correlation between standardized uptake value (SUVmax), tumor size and Fuhrman grade in patients with renal cell carcinoma (RC). Materials and Methods: We retrospectively analyzed the data of 54 patients with clear cell renal cell carcinoma histopathologically diagnosed who underwent fluorine-18 fluoro-2 deoxyglucose positron emission tomography/computed tomography (F-18 FDG PET/CT) between January 2005 and March 2014. Results: Avarage tumor sizes were 5.64 $\pm 1.85,6.85 \pm 2.24$ and $7.98 \pm 2.45$ in low, medium and high SUVmax groups, respectively. The Spearman's correlation coefficient between the tumor size and SUVmax was 0.385 ( $p=0.004$ ) and between the Fuhrman grade and SUVmax was 0.578 (p<0.001). Conclusions: SUVmax appears highly correlated with tumor size and Fuhrman grade in patients with histopathologically confirmed clear cell RC. Multicenter studies are needed to provide larger series for more accurate results.
\end{abstract}

Keywords: F-18 FDG PET/CT - SUVmax - renal carcinoma - Fuhrman grade - tumor size

Asian Pac J Cancer Prev, 15 (18), 7821-7824

\section{Introduction}

Renal cancers account for around $3 \%$ of all cancers (Ferlay et al., 2007) and the most common type (90\%) is renal cell carcinoma (RC) (Motzer et al., 1996). Five-year survival rate in renal cancer patients is $68.4 \%$ all over the globe (Horner et al., 2010). There has been an increase in the number of serendipitiously detected renal tumors in asymptomatic individuals with the widespread use of conventional imaging modalities including computed tomography (CT), magnetic resonance imaging (MRI), and ultrasonography (US) (Jayson and Sanders, 1998; Luciani et al., 2000). For solid renal masses, presence of enhancement is the most important criterion for differentiating malignant lesions (Israel and Bosniak, 2008). Fluorine-18 fluoro-2 deoxyglucose (FDG) positron emission tomography (PET) has been recognised as an efficient imaging modality for the management of oncology patients and has been used increasingly for primary staging, detection of recurrence, assessment of residual masses and monitoring therapeutic response in various types of cancers (Bomanji et al., 2001). Also it has become an important tool for the detection of bone metastasis (Liu et al., 2013).

Numerous recent studies of various types of malignancies have reported an association between the
18-F-FDG accumulation rate evaluated by PET and patient prognosis. The standardized uptake value (SUV) is a semiquantitative simplified measurement of the tissue FDG accumulation rate, and the recent studies of the head-and-neck, esophagus, lung, and cervical cancer have explored the prognostic significance of the maximum standardized uptake value (SUVmax) (Sasaki et al., 2005; Lee et al., 2009; Ma et al., 2013; Uzel et al., 2013; Zhu et al., 2013). Although several number of studies have investigated the usage of PET/CT in the evaluation of $\mathrm{RC}$, its connection with tumor size and nuclear grade are not researched enough in literature. We retrospectively investigated the correlation between SUVmax, tumor size and Fuhrman grade in patients with histopathologically shown renal cell carcinoma.

\section{Materials and Methods}

We retrospectively analyzed the data of 54 patients (32 men, 22 women, age range $34-76$ years, mean age $53.8 \pm 12.4$ years) with clear cell renal cell carcinoma histopathologically who underwent F-18 FDG PET/CT in Okmeydanı Education and Research Hospital between January 2005 and March 2014.

The size of the renal masses ranged from 3 to 15 $\mathrm{cm}$, with a mean size of $6.4 \pm 3.9 \mathrm{~cm}$. Histologic subtype

\footnotetext{
${ }^{1}$ Faculty of Medicine, Istanbul Medipol University, ${ }^{2}$ Okmeydani Training and Research Hospital, Istanbul, ${ }^{3}$ Department of Urology, Faculty of Medicine, Izmir Katip Celebi University, Izmir Ataturk Training and Research Hospital, Izmir, Turkey *For correspondence: dremrecan@hotmail.com
} 
was determined according to the 1997 World Health Organization Heidelberg classification and tumor nuclear grading was performed according to the Fuhrman nuclear grading system. PET/CT was carried out using an integrated PET/CT scanner, which consisted of a full-ring HI-REZ LSO PET and a six-slice CT (Siemens Biograph 6; Siemens, Chicago, Illinois, USA). Studies were performed after at least 6 hours fasting and with the glucose level lower than $150 \mathrm{mg} / \mathrm{dl}$. The CT portion of the study was carried out without an intravenous contrast medium, just for defining anatomical landmarks and making attenuation correction on PET images. CTwas acquired first with the following parameters: 50mAs, $140 \mathrm{kV}$, and 5-mm section thickness. Whole-body CT was performed in a craniocaudal direction. PET images were acquired in a three-dimensional mode, from the base of the skull to the midthigh, with five-to-seven bed positions of 3 min each and PET data were collected in a caudocranial direction. The CT data were matched and fused with the PET data. The SUVmax was calculated using the following formula: $\mathrm{SUV}=\mathrm{cdc} /(\mathrm{d} / \mathrm{w})$, where cdc is the decay-corrected tracer tissue concentration (in $\mathrm{Bq} / \mathrm{g}$ ); d, the injected dose (in Bq); and w, the patient's body weight (in $\mathrm{g}$ ).

We divided the tumors into 3 groups according to the tertile of the SUVmax value, a low group (SUVmax $\leq 2.54$ ), medium group (2.54<SUVmax $\leq 4.61)$, and a high group (SUVmax $\geq 4.61$ ) (Harada et al., 2011). Analyses were done using Chi-square tests, Kruskal Wallis test and Mann-Whitney U tests. We also calculated the Spearman's correlation coefficient between SUVmax, Fuhrman grade and tumor size. We considered a p-value $<0.05$ (two-sided test) to be a statistically significant difference. All analysis were conducted using SPSS version 15.0 (SPSS Inc., Chicago, Illinois, USA).

\section{Results}

Among the 3 tumor groups established according to the SUVmax values, the tumor size and the Fuhrman grade were significantly different (Table 1 , Table 2). Avarage tumor sizes were $5.64 \pm 1.85,6.85 \pm 2.24$ and $7.98 \pm 2.45$ in low, medium and high SUVmax groups, respectively. Especially, highly statistical significant difference was detected between low and high SUVmax groups in

Table 1. Relationship between SUVmax and Tumor Size

\begin{tabular}{|c|c|c|c|c|c|}
\hline & & $\begin{array}{c}\text { Low } \\
\text { SUV } \\
\max \leq 2.54 \\
\text { No } \%\end{array}$ & $\begin{array}{c}\text { Medium } \\
2.54<\text { SUV } \\
\max \leq 4.61 \\
\text { No } \%\end{array}$ & $\begin{array}{c}\text { High } \\
\text { SUV } \\
\max \geq 4.61 \\
\text { No } \%\end{array}$ & P-value \\
\hline $\begin{array}{l}\text { Tumor size } \\
(\mathrm{cm})\end{array}$ & & $\begin{array}{l}5.64 \pm 1.85 \\
5.64 \pm 1.85 \\
5.64 \pm 1.85 \\
6.85 \pm 2.24\end{array}$ & $\begin{array}{l}6.85 \pm 2.24 \\
6.85 \pm 2.24 \\
7.98 \pm 2.45 \\
7.98 \pm 2.45\end{array}$ & $\begin{array}{l}7.98 \pm 2.45 \\
0.196 \\
0.006^{*} \\
0.15\end{array}$ & $0,019 *$ \\
\hline $\begin{array}{l}\text { Tumor size } \\
(\mathrm{cm}) \\
\mathrm{X}^{2} \\
\mathrm{P} \text {-value }\end{array}$ & $\begin{array}{c}\leq 7 \mathrm{~cm} \\
>7 \mathrm{~cm} \\
8.74 \\
0.013\end{array}$ & $\begin{array}{c}11.20 \% \\
3.6 \%\end{array}$ & $\begin{array}{l}7.13 \% \\
9.17 \%\end{array}$ & $\begin{array}{r}7.13 \% \\
17.31 \%\end{array}$ & \\
\hline
\end{tabular}

Table 2. Relationship between SUVmax and Fuhrman Grade

\begin{tabular}{lcccc}
\hline & Low & Medium & High \\
& & SUV & $2.54<$ SUV & SUV \\
& & max $\leq 2.54$ & $\max \leq 4.61$ & $\max \geq 4.61$ \\
& & No $\%$ & No $\%$ \\
\hline Fuhrman grade & Low $(1,2)$ & $10.19 \%$ & $7.13 \%$ & $5.9 \%$ \\
& High $(3,4)$ & $4.7 \%$ & $9.17 \%$ & $19.35 \%$ \\
$X^{2}$ & 9.461 & & & \\
P-value & 0.009 & & & \\
*P-value was calculated using the Chi-square test & & & \\
\end{tabular}

Table 3. The Spearman's Correlation Coefficient between SUVmax, Tumor Size and Fuhrman Grade

\begin{tabular}{llccc}
\hline & & SUVmax & $\begin{array}{c}\text { Tumor } \\
\text { size }\end{array}$ & $\begin{array}{c}\text { Fuhrman } \\
\text { grade }\end{array}$ \\
\hline SUVmax & $\mathrm{R}$ & 1.000 & $0.385^{*}$ & $0.578^{*}$ \\
& $\mathrm{p}$ value (two-sided) & & 0.004 & 0.000 \\
Tumor size & $\mathrm{N}$ & 54 & 54 & 54 \\
& $\mathrm{R}$ & $0.385^{*}$ & 1.000 & $0.479 *$ \\
& $\mathrm{p}$ value (two-sided) & 0.004 & & 0.000 \\
Fuhrman grade & $\mathrm{N}$ & 54 & 54 & 54 \\
& $\mathrm{R}$ & $0.578^{*}$ & $0.479 *$ & 1.000 \\
& $\mathrm{p}$ value (two-sided) & 0.000 & 0.000 & \\
& $\mathrm{~N}$ & 54 & 54 & 54 \\
\hline
\end{tabular}

*Significant correlation at the level $\mathrm{p}<0.01$. (two-sided)

terms of tumor size $(\mathrm{p}=0.006)$ (Table 1$)$. Tumor size and Fuhrman grade were found significantly higher in the high SUVmax group $(\mathrm{p}<0.05)$.

The Spearman's correlation coefficient between the tumor size and SUVmax was $0.385(\mathrm{p}=0.004)$, indicated that the tumor size and SUVmax were in moderate correlation and the Spearman's correlation coefficient between the Fuhrman grade and SUVmax was 0.578 $(\mathrm{p}<0.001)$, indicating that the Fuhrman grade and SUVmax were highly correlated (Table 3 ).

\section{Discussion}

Renal cell carcinoma (RCC-clear cell type) is the most frequent renal solid tumor. The role of imaging tests is fundamental for its diagnosis. At present, CT scan is the most widely employed method to evaluate renal mass, providing precise information on adjacent and distant organ involvement (Powles and Ell, 2007; Powles et al., 2007). MRI and US are alternative imaging modalities that are also useful, particularly in patients who have contraindications to contrast-enhanced CT and for the evaluation of pediatric and pregnant patients given the lack of radiation dose ( $\mathrm{Ng}$ et al., 2008).

Wahl et al (1991). first reported the possible value of 18F-FDG PET for the diagnosis of renal cancers in 1991. The reported sensitivities and specificities of 18F-FDGPET in subsequent studies have generally been suboptimal in comparison to diagnostic CT or MRI, with sensitivities ranging from 40\%-94\% and specificities ranging from 0\%-100\% (Kocher et al., 1994; Goldberg et al., 1997; Bachor et al., 1996; Montravers et al., 2000; Ramdave et al., 2001; Miyakita et al., 2002; Aide et al., 2003; Kang et al., 2004; Ak and Can, 2005; Kumar et al., 2005; Martinez et al., 2007). The low sensitivity of 18F-FDG- 
PET in some reports has been attributed to FDG excretion through the kidneys and collecting systems, decreasing contrast between renal lesions and normal tissues, as well as due to significant variability of $18 \mathrm{~F}-\mathrm{FDG}$ uptake that may be related to variable expression of GLUT-1 glucose transporters, tumor grade, presence of central necrosis, and/or lack of accessibility of 18F-FDG (Bachor et al., 1996; Miyauchi et al., 1996; Montravers et al., 2000; Miyakita et al., 2002; Aide et al., 2003). As we did not evaluate benign and malignant renal masses other than clear cell type, we did not calculate the specificity of 18F-FDG-PET/CT.

Khandani et al (Khandani et al., 2012) reported an avarage SUVmax 3.9 (range 1.7-9.5) for clear cell RC and 7.9 (range 2.7-13.9) for non-clear cell RC. In our study although we only anlyze the clear cell subtype, 15 patients had higher SUVmax values than 7.9 and also 4 patients had higher SUVmax values than 13.9. Accordingly; we believe that determination of theavarage. SUVmax value for renal tumors and its subtypes, larger groups of patients should be examined.

A few studies have evaluated the influence of histological and biochemical characteristics of renal tumours on their visualisation by either FDG PET or other radiotracers, and their results are discordant. Miyauchi et al. (Miyauchi et al., 1996) concluded that renal cancers well visualised by FDG PET had a higher Fuhrman grade and higher GLUT-1 expression and tended to be larger than the poorly visualised tumours. In contrast, Miyakita et al. (Miyakita et al., 2002) found no correlation between GLUT 1 expression in renal tumours and their visualisation by FDG PET.

Ozulker et al. (Ozulker et al., 2011) found a significant correlation between size and FDG uptakes of tumors as well-visualized tumors were larger than nonvisualized tumors $(\mathrm{p}<0.05)$ and found a relation between Fuhrman grades of tumors and FDG avidity because the grades of FDG-positive tumors were significantly higher than the grades of FDG-negative tumors $(p<0.05)$. In other studies PET results were not related to Fuhrman score or histological type of primary tumor. (Majhail et al., 2003; Nakatani et al., 2009; Bertagna et al., 2013) Nakhoda et al. (Nakhoda et al., 2013) suggested that 18F-FDG-PET/ CT may be useful to assess RC tumor biology according to the clear cell RC subtype had significantly greater levels of metabolism compared to the papillary RC.

Namura et al. (Namura et al., 2010) revealed that the SUVmax has the potency as a novel biomarker to predict the survival time of patients with advanced RC and our findings indicate that high SUVmax values are associated with bigger tumor size and higher nuclear grade in patients with clear cell RC.

In conclusion, despite the limitations of our study due to the retrospective type of evaluation and the absence of survival analysis, we found an excellent correlation between SUVmax, tumor size and Fuhrman grade in patients with histopathologically shown clear cell RC. We agree the opinion that SUVmax value is a prognostic factor in RC patients. Additional studies with an expanded number of patients and period of follow-up are necessary.

\section{References}

Aide N, Cappele O, Bottet P, et al (2003). Efficiency of [18F] FDG PET in characterising renal cancer and detecting distant metastases: a comparison with CT. Eur J Nucl Med Mol Imaging, 30, 1236-45.

Ak I, Can C (2005). F-18 FDG PET in detecting renal cell carcinoma. Acta Radiol, 46, 895-9.

Bachor R, Kotzerke J, Gottfried HW, et al (1996). Positron emission to-mography in diagnosis of renal cell carcinoma. Urologe A, 35, 146-50.

Bertagna F, Motta F, Bertoli M, et al (2013). Role of F18-FDG$\mathrm{PET} / \mathrm{CT}$ in restaging patients affected by renal carcinoma. Nucl Med Rev Cent East Eur, 16, 3-8.

Bomanji JB, Costa DC, Ell PJ (2001). Clinical role of positron emission tomography in oncology. Lancet Oncol, 2, 157-164.

Downey RJ, Akhurst T, Gonen M, et al (2004). Preoperative F-18 fluorodeoxyglucose-positron emission tomography maximal standardized uptake value predicts survival after lung cancer resection. J Clin Oncol, 22, 3255-60.

Ferlay J, Autier P, Boniol M, et al (2007). Estimates of the cancer incidence and mortality in Europe in 2006. Ann Oncol, 18, 581-92.

Goldberg MA, Mayo-Smith WW, Papanicolaou N, Fischman AJ, Lee MJ (1997). FDG PET characterization of renal masses: preliminary experience. Clin Radiol, 52, 510-5.

Harada S, Sato S, Suziki E, et al (2011). The Usefulness of PreRadiofrequency Ablation $\mathrm{SUV}_{\max }$ in ${ }^{18} \mathrm{~F}$-FDG PET/CT to Predict the Risk of a Local Recurrence of Malignant Lung Tumors after Lung Radiofrequency Ablation. Acta Med Okayama, 65, 395-402.

Horner MJ, Ries LAG, Krapcho M, et al (2010). SEER cancer statistics review, 1975-2006. Bethesda, MD: National Cancer Institute.

Israel GM, Bosniak MA(2008). Pitfalls in renal mass evaluation and how to avoid them. Radiographics, 28, 1325-38.

Jayson M, Sanders H (1998). Increased incidence of serendipitously discovered renal cell carcinoma. Urology, 51, 203-5.

Kang DE, White RL, Jr., Zuger JH, Sasser HC, Teigland CM (2004). Clinical use of fluorode-oxyglucose F-18 positron emission tomography for detection of renal cell carcinoma. J Urol, 171, 1806-9.

Khandani AH, Cowey CL, Moore DT, Gohil H, Rathmell WK (2012). Primary renal cell carcinoma: relationship between 18F-FDG uptake and response to neoadjuvant sorafenib. Nucl Med Commun, 33, 967-73.

Kocher F, Geimmel S, Hauptmann R, Reske SN (1994). Preoperative lymph node staging in patients with kidney and urinary bladder neoplasm. J Nucl Med, 35, 223.

Kumar R, Chauhan A, Lakhani P, et al (2005). 2-Deoxy-2[F-18]fluoro- D-glucose-positron emission tomography in characterization of solid renal masses. Mol Imaging Biol, 7, 431-9.

Lee YY, Choi CH, Kim CJ, et al (2009). The prognostic significance of the SUVmax (maximum standardized uptake value for F-18 fluorodeoxyglucose) of the cervical tumor in PET imaging for eary cervical cancer: Preliminary results. Gynecol Oncol, 115, 65-68.

Liu NB, Zhu L, Li MH, et al (2013). Diagnostic value of 18F-FDG PET/CT in comparison to bone scintigraphy, CT and 18F-FDG PET for the detection of bone metastasis. Asian Pac J Cancer Prev, 14, 3647-52.

Luciani LG, Cestari R, Tallarigo C (2000). Incidental renal cell carcinoma: age and stage characterization and clinical implications, study of 1092 patients (1982-1997). Urology, 


$$
\text { 56, 58-62. }
$$

Ma JB, Chen EC, Song YP, et al (2013). Prognostic significance of $18 \mathrm{~F}$-fluorodeoxyglucose positron emission tomography (PET)-based parameters in neoadjuvant chemoradiation treatment of esophageal carcinoma. Asian Pac J Cancer Prev, 14, 2477-81.

Majhail NS, Urbain JL, Albani JM, et al (2003). F-18 fluorodeoxyglucose positron emission Tomography in the evaluation of distant metastases from renal cell carcinoma. J Clin Oncol, 21, 3995-4000.

Martinez de Llano SR, Delgado-Bolton RC, Jimenez-Vicioso A, et al (2007). Meta-analysis of the diagnostic performance of 18F-FDG PET in renal cell carcinoma. Rev Esp Med Nucl, 26, 19-29.

Miyakita H, Tokunaga M, Onda H, et al (2002). Significance of $18 \mathrm{~F}$-fluorodeoxyglucose positron emission tomography (FDG-PET) for detection of renal cell carcinoma and immunohistochemical glucose transporter 1 (GLUT-1) expression in the cancer. Int J Urol, 9, 15-8.

Miyauchi T, Brown RS, Grossman HB, Wojno K, Wahl RL (1996). Correlation between visualization of primary renal cancer by FDG-PET and histopathological findings. $\mathrm{J} \mathrm{Nucl}$ Med, 37, 64.

Montravers F, Grahek D, Kerrou K, et al (2000). Evaluation of FDG up-take by renal malignancies (primary tumor or metastases) us-ing a coincidence detection gamma camera. J Nucl Med, 41, 78-84.

Motzer RJ, Bander NH, Nanus DM (1996). Renal-cell carcinoma. $N$ Engl J Med, 335, 865-75.

Nakatani K, Nakamoto Y, Saga T, Higashi T, Togashi K (2009). The potential clinical value of FDG-PET for recurrent renal cell carcinoma. Eur J Radiol, 79, 29-35.

Nakhoda Z, Torigian DA, Saboury B, Hofheinz F, Alavi A (2013). Assessment of the diagnostic performance of 18F-FDG-PET/CT for detection and characterization of solid renal malignancies. Hell J Nucl Med, 16, 19-24.

Namura K, Minamimoto R, Yao M, et al (2010). Impact of maximum Standardized Uptake Value (SUVmax) evaluated by 18-Fluoro-2-deoxy-Dglucose positron emission tomography/computed tomography (18F-FDG-PET/CT) on survival for patients with advanced renal cell carcinoma: a preliminary report. BMC Cancer, 10, 667.

$\mathrm{Ng}$ CS, Wood CG, Silverman PM, et al (2008). Renal cell carcinoma: diagnosis, staging, and surveillance. Am J Roentgenol, 191, 1220-32.

Ozulker T, Ozulker F, Ozbek E, Ozpacaci T (2011). A prospective diag-nostic accuracy study of F-18 fluorodeoxyglucosepositron emission tomography/computed tomography in the evaluation of indeterminate renal masses. Nucl Med Commun, 32, 265-72.

Powles T, Ell PJ (2007). Does PET imaging have a role in renal cancers after all? Lancet Oncol, 8, 279-81.

Powles T, Murray I, Brock C, Oliver T, Avril N (2007). Molecular positron emission tomography and $\mathrm{PET} / \mathrm{CT}$ imaging in urological malignancies. Eur Urol, 51, 1511-20.

Ramdave S, Thomas GW, Berlangieri SU, et al (2001). Clinical role of F-18 fluorodeoxyglucose positron emission tomography for de-tection and management of renal cell carcinoma. J Urol, 166, 825-30.

Sasaki R, Komaki R, Macapinlac H, et al (2005). [18F] fluorodeoxyglucose uptake by positron emission tomographypredicts outcome of non-small-cell lung cancer. J Clin Oncol, 23, 1136-43.

Uzel EK, Ekmekcioglu O, Elicin O, Halac M, Uzel OE (2013). Is FDG -PET-CT a valuable tool in prediction of persistent disease in head and neck cancer. Asian Pac J Cancer Prev, 14, 4847-51.
Wahl RL, Harney J, Hutchins G, Grossman HB (1991). Imaging of renal cancer using positron emission tomography with 2-deoxy-2-(18-F)-fluoro-Dglucose: pilot animal and human studies. J Urol, 146, 1470-4.

Zhu SH, Zhang Y, Yu YH, et al (2013). FDG PET-CT in nonsmall cell lung cancer: relationship between primary tumor FDG uptake and extensional or metastatic potential. Asian Pac J Cancer Prev, 14, 2925-9. 